\title{
Preface for the Special Edition of Geographical Review of Japan Series B
}

\section{KIKUCHI Toshio* and TAIRA Atsushi**}

*Department of Tourism Science, Graduate School of Urban Environmental Sciences, Tokyo Metropolitan University,

1-1, Minamiosawa, Hachioji-shi, Tokyo, 192-0397, Japan

**Faculty of Education, Kagawa University, Takamatsu, Kagawa 760-8522, Japan

E-mail: kikuchan@tmu.ac.jp*, taira@ed.kagawa-u.ac.jp**

The articles, which appear following this preface, are written by three authors among the "Young Geographer Prize" winners at the 5th Japan-Korea-China Joint Conference on Geography held at Sendai, Japan, in November, 2010. The Japan-Korea-China Conference on Geography was created by a number of Japanese, Chinese and Korean geographers to encourage young scholars to give presentations in English in an international conference atmosphere. The first conference was successfully held in Beijing, China in 2006. The second conference was held in Kumamoto in 2007 and the third one in Cheongju, Korea in 2008, with increasing numbers of participants. When the organizing committee of the 5th joint conference was preparing the conference, a new idea of creating young geographer awards came about and that idea was realized during the conference. Young Geographer Prize was awarded to a limited number of excellent papers and posters through careful selection processes by the prize committee members.
After the conference, the organizing committee of the conference asked the executive board of the Association of Japanese Geographers (AJG) to prepare a special edition in the Geographical Review of Japan Series B for papers which were awarded the Young Geographer Prize. That request was kindly accepted by the executive board of the AJG. After this decision, we requested the winners of the prize to submit their papers to this journal. As a result, three papers were submitted and accepted by the editorial board of Geographical Review of Japan Series B through the regular peer-review processes. The following three papers are those accepted papers.

Sendai and Tohoku University, where the 5th Japan-Korea-China Joint Conference on Geography mentioned above was held, was hit and damaged by the Great Earthquake of Eastern Japan on March 11, 2011. Taking this opportunity, we would like to express our condolences to all those who lost their families and friends. 